University of South Carolina

Scholar Commons

8-21-2012

\title{
Mammalian PER2 Regulates AKT Activation and DNA Damage Response
}

Xiaoming Yang

Xuezhong He

Zhengguan Yang

Esmaiel Jabbari

University of South Carolina - Columbia, jabbari@engr.sc.edu

Follow this and additional works at: https://scholarcommons.sc.edu/eche_facpub

\section{Publication Info}

Published in Biochemistry and Cell Biology, Volume 90, Issue 6, 2012.

This Article is brought to you by the Chemical Engineering, Department of at Scholar Commons. It has been accepted for inclusion in Faculty Publications by an authorized administrator of Scholar Commons. For more information, please contact digres@mailbox.sc.edu. 


\title{
Mammalian PER2 regulates AKT activation and DNA damage response
}

\author{
Xiaoming Yang, Xuezhong He, Zhengguan Yang, and Esmaiel Jabbari
}

\begin{abstract}
PER2 is a key mammalian circadian clock protein. It also has a tumor suppressive function. Down regulation of PER2 in the cultured cancer cells accelerates cell proliferation, while overexpression of PER2 inhibits cell growth and induces apoptosis. The Per 2 mutant mice have a cancer prone phenotype and an altered DNA damage response. Here we report that PER2 regulates AKT activity. Cells with down-regulated PER2 expression have prolonged high levels of AKT T308 phosphorylation after growth factor stimulation or DNA damage. PER2 down-regulation delays DNA damage induced Chk2 activation and overrides DNA damage induced apoptosis and cell cycle arrest.
\end{abstract}

Key words: PER2, AKT, tumor suppressor, DNA damage response.

Résumé : PER2 est une protéine clé de l'horloge circadienne des mammifères. Elle possède également une fonction suppressive des tumeurs. La régulation à la baisse de PER2 chez des cellules cancéreuses en culture accélère la prolifération alors qu'une surexpression de PER2 inhibe la croissance cellulaire et induit l'apoptose. Des souris Per2 mutantes possèdent un phénotype de susceptibilité au cancer et une réponse déficiente aux dommages à l'ADN. Nous rapportons ici que PER2 régule l'activité d'AKT. Le haut niveau de phosphorylation d'AKT T308 se maintient plus longtemps après une stimulation par facteur de croissance ou des dommages à l'ADN chez les cellules où l'expression de PER2 est régulée à la baisse. La régulation à la baisse de PER2 retarde l'activation de Chk2 induite par les dommages à l'ADN, et annule l'apoptose et l'arrêt du cycle cellulaire induits par les dommages à l'ADN.

Mots-clés : PER2, AKT, suppresseur de tumeur, réponse au dommage à l'AND.

[Traduit par la Rédaction]

\section{Introduction}

In the mammalian clockwork, the Period genes (Perl, 2) are among the most critical clock genes (Reppert and Weaver 2002). In addition to their roles in controlling mammalian circadian rhythms, several lines of evidence suggest that the Period genes also have unique tumor suppressive functions. For example, Per2 mutant mice not only have a disrupted circadian clock but also show deregulated expressions of cell cycle control genes (c-Myc, Cyclin D1, Gadd45, Mdm2) and an abnormal DNA damage response, thus leading to a cancer prone phenotype (Fu et al. 2002). In human tumor tissues, PER1 and PER 2 are often deregulated. Decreased PER2 RNA levels have been reported in acute leukemias and in breast tumors (Gery et al. 2005; Winter et al. 2007). Abnormalities in PER2 (and PERI) promoter methylation and asynchronous protein expression have also been observed in breast tumors (Chen et al. 2005). Furthermore, it has been reported that a decreased level of PER2 in colorectal tumors predicts a poor survival (Iacobelli et al. 2008; Oshima et al. 2011; Zeman et al. 2008).

We have shown that Per 2 mutant mice develop colonic polyps and have increased expressions of $\beta$-catenin and its downstream genes (Wood et al. 2008). In addition, introduction of Per2 mutation into $\mathrm{Apc}^{\mathrm{Min} /+}$ mice enhances $\mathrm{Apc} \mathrm{Min} /+^{-+}$ associated phenotypes, including increased intestinal polyp number, anemia, and increased spleen weight (Wood et al. 2008). We have also shown that down-regulation of PER2 increases the growth of cancer cells under normal growth conditions (Wood et al. 2008; Yang et al. 2009). Others have shown that over expression of PER2 inhibits cell proliferation and enhances apoptosis in both cultured cancer cells and transplanted tumors (Gery and Koeffler 2009; Hua et al. 2006, 2007). However, it is unclear how PER2 exerts its tumor suppressive function.

AKT is a key regulator of $\beta$-catenin expression and cell proliferation (Liang and Slingerland 2003; Liao and Hung 2010). AKT inhibits apoptosis and promotes cell growth, and its overactivation has been implicated in several types of cancer (Cicenas 2008). After growth factor stimulation, PI3K generates messenger molecule PIP3, which recruits AKT to the cell membrane where it is phosphorylated at the T308 site by PDK1 and at the S473 site by mTORC2. The activated AKT phosphorylates its substrates, such as GSK3 $\beta$ at the S9 site, and this inactivates GSK3 $\beta$ (MacDonald et al. 2009). AKT is also phosphorylated by DNA-PK after DNA

Received 5 January 2012. Revision received 6 June 2012. Accepted 25 June 2012. Published at www.nrcresearchpress.com/bcb on 21 August 2012.

X. Yang. Dorn Research Institute, 6439 Garners Ferry Rd, Columbia, SC 29209, USA.

X. He and E. Jabbari. Department of Chemical Engineering, University of South Carolina, Columbia, SC, USA.

Z. Yang. Department of Pharmaceutical and Biomedical Science, University of South Carolina, Columbia, SC, USA.

Corresponding author: Xiaoming Yang (e-mail: xiaoming.yang@va.gov). 
Fig. 1. PER2 deficiency enhances AKT activation after growth factor stimulation. After HCT116 cells were treated with siRNA (Luciferase siRNA as control and PER2 siRNA set 1) for $48 \mathrm{~h}, 100 \mathrm{ng} / \mathrm{mL}$ of IGF-1 was added to the medium. Samples were taken at the indicated time points. The relative amounts of PER2 mRNA were determined by real time PCR. The amount in the control cells at time point 0 was set as 1 (A). The amounts of phosphorylated AKT and GSK3 $\beta$, and total level of PTEN, were examined by specific antibodies. GAPDH was the loading control (B). Quantification of AKT T308, S473, and GSK3 $\beta$ S9 in the control (gray bars) and PER2 knockdown (empty bars) cells after IGF-1 stimulation. The levels before the treatment in control cells were set as 1 (C). PER2 was down-regulated by PER2 siRNA set 2 in HCT 116 cells. Cells were treated by $100 \mathrm{ng} / \mathrm{mL}$ of IGF-1 for the indicated time. The relative amounts of PER 2 mRNA were determined by real time PCR. The amount in the control cells at time point 0 was set as 1 (D). The phosphorylation levels of AKT T308, S473, and GSK3 $\beta$ S9 were determined by Western blotting (E). Primary MEF cells were isolated from wild type or Per $2^{\mathrm{m} / \mathrm{m}}$ mice. The genotype was determined by PCR according to the protocol provided by Jackson Laboratory cells were treated with 100ng/mL of IGF-1 for the indicated time. The T308 phosphorylated and total AKT were compared (F).

damage (Bozulic et al. 2008). However, AKT overactivation leads to the inhibition of DNA damage response (Xu et al. 2010). Here we report that PER2 may exert its tumor suppressive function by regulating AKT activity. We demonstrate that PER2-depleted cells have a higher level of phosphorylated AKT. Furthermore, down-regulation of PER2 leads to a prolonged AKT activation after growth factor stimulation or DNA damage. Enhanced AKT activity in PER2 down-regulated cells attenuates doxorubicin induced DNA damage response and renders cells resistant to chemotherapy drugs.

\section{Materials and methods}

\section{Cell Culture and siRNA}

HCT116 and SW480 human colon cancer cells obtained from ATCC (Manassas, Va., USA) were maintained in RPMI 1640 medium with 10\% fetal bovine serum (FBS) under the condition of $5 \% \mathrm{CO}_{2}$ at $37{ }^{\circ} \mathrm{C}$. For siRNA transfection, cells were plated in 6-well plates the day before to reach $30 \%$ confluency by the time of transfection. siRNA oligos $(200$ pmol) were transfected by Lipofectmine2000 (Invitrogen, Carlsbad, Calif., USA) according to the protocol provided by the manufacturer. The knockdown efficiency was examined after $48-72 \mathrm{~h}$ of incubation by real-time PCR. The sequences of human PER2 siRNA were designed by Blockit siRNA Designer (Invitrogene). Sequences of RNA oligos were as follows:

1. Control (Luciferase): 5'-CGUAACGCGGAAUACUUCGAdTdT-3' and 5'-UCGAAGUAUUCCGCGUACGdTdT-3'

2. PER2 (Set 1): 5'-GCGUUACCUCUGAGCACAUdTdT-3' and 5'-AUGUGCUCAGAGGUAACGCdTdT-3'

3. PER2 (Set 2): GCGCUAAGGUCCAGUGAUAdTdT- $3^{\prime}$ and 5'-UAUCACUGGACCUUAGCGCdTdT-3'

The sequences for real time PCR quantification of human PER2 were:

1. PER2 Forward: 5'-CCTCTCCTGGGCTACCTACC-3' and

2. PER2 Reverse: 5'-CCTCCCAATGATGAAGGAGA-3'

$G A P D H$ was used as a control for real time PCR. The sequences for $G A P D H$ were:

1. GAPDH Forward: 5'-GAGTCAACGGATTTGGTCGT-3' and

2. GAPDH Reverse: 5'-TTGATTTTGGAGGGATCTCG-3'

MEF cells were generated from the wild type C57BL/6J and $P e r 2^{m / m}$ mice (Jackson laboratory, Bar Harbor, Maine, USA). Per $2^{\mathrm{m} / \mathrm{m}}$ mice had been backcrossed into C57BL/6J background for 10 generations. MEF cells were cultured in DMEM with $10 \%$ FBS.

\section{Western blot and antibodies}

After $48 \mathrm{~h}$ of siRNA transfection, cells were treated with doxorubicin (Sigma, St. Louis, Mo., USA) for the indicated time, or treated for $2 \mathrm{~h}$ then incubated in the drug free medium. Cells were washed with PBS once, and total protein extracts were obtained by incubating in NP-40 buffer $(0.5 \%$ NP-40, $150 \mathrm{mmol} / \mathrm{L} \mathrm{NaCl}, 50 \mathrm{mmol} / \mathrm{L}$ Tris-Cl pH7.4, protease inhibitors). Proteins were then separated by standard SDS-PAGE and transferred to nitrocellulose membranes. Antibodies against Chk2 T68, AKT T308, AKT S473, GSK3 $\beta$ S9, and $\gamma-\mathrm{H} 2 \mathrm{AX}$ were from Cell Signaling Technology (Danvers, Mass., USA). Anti-PER2 antibodies were from Alpha Diagnostic International (San Antonio, Tex., USA). Other antibodies were from Santa Cruz Biotechnology (Santa Cruz, Calif., USA). AKT1/2 inhibitor was from Sigma and dissolved in DMSO. All experiments were repeated at least 3 times. Images were quantified by Image $\mathrm{J}$ software $(\mathrm{NIH}$, USA). Statistic difference was determined by $t$ test and annotated with an asterisk.

\section{Drug sensitivity assay}

After siRNA treatment for $48 \mathrm{~h}$, cells were incubated with the indicated concentration of drug for $24 \mathrm{~h}$. Then cells were washed with PBS, trypsinized, and seeded in the drug-free medium. Cells were fixed with methanol and stained with crystal violet solution after 1 week of incubation. Colonies were counted.

\section{Results}

\section{PER2 deficient cells have enhanced AKT activity}

The increased proliferation of PER2 down-regulated cells prompted us to further investigate the underlying mechanism. It has been reported that the endothelial cells of Per2 mutant mice exhibit AKT-dependent senescence (Wang et al. 2008). Since we have observed that Per 2 mutation enhances intestinal tumorigenesis in mice, we used colorectal cancer cells to investigate the role of PER2 in vitro. Down-regulation of PER2 in HCT116 cells increased the basal level of T308 phosphorylated AKT (Figs. 1 A and 1B). IGF-1, a growth factor, acutely stimulated AKT phosphorylation at both T308 and S473 sites (Figs. 1B and 1C). AKT phosphorylations gradually reduced over the time in the control cells. However, PER2 knockdown cells had prolonged high levels of AKT T308 phosphorylation, while the levels of S473 phosphorylated AKT did not differ between the control and PER2 
A.

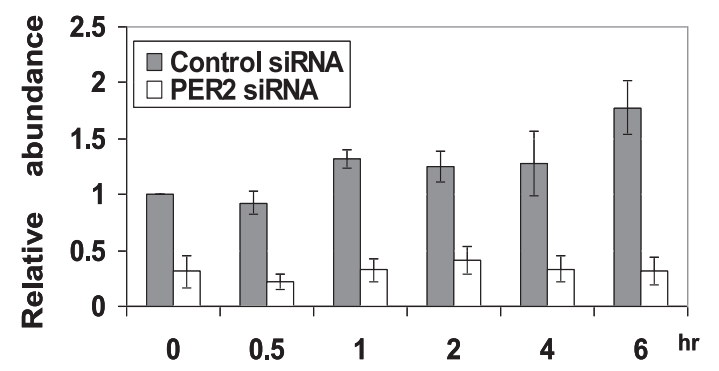

B. Control SIRNA PER2 SIRNA

$\begin{array}{lllllllllll}0 & 0.51 & 2 & 4 & 6 & 0 & 0.512 & 4 & 6 & \text { hr IGF-1 }\end{array}$
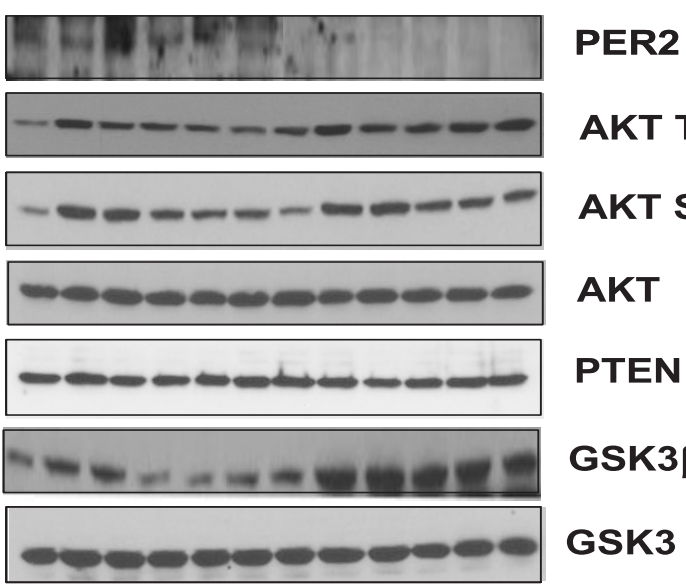

AKT T308

AKT 5473

AKT

PTEN

GSK3 $\beta$ S9

GSK3 $\beta$

GAPDH

C.

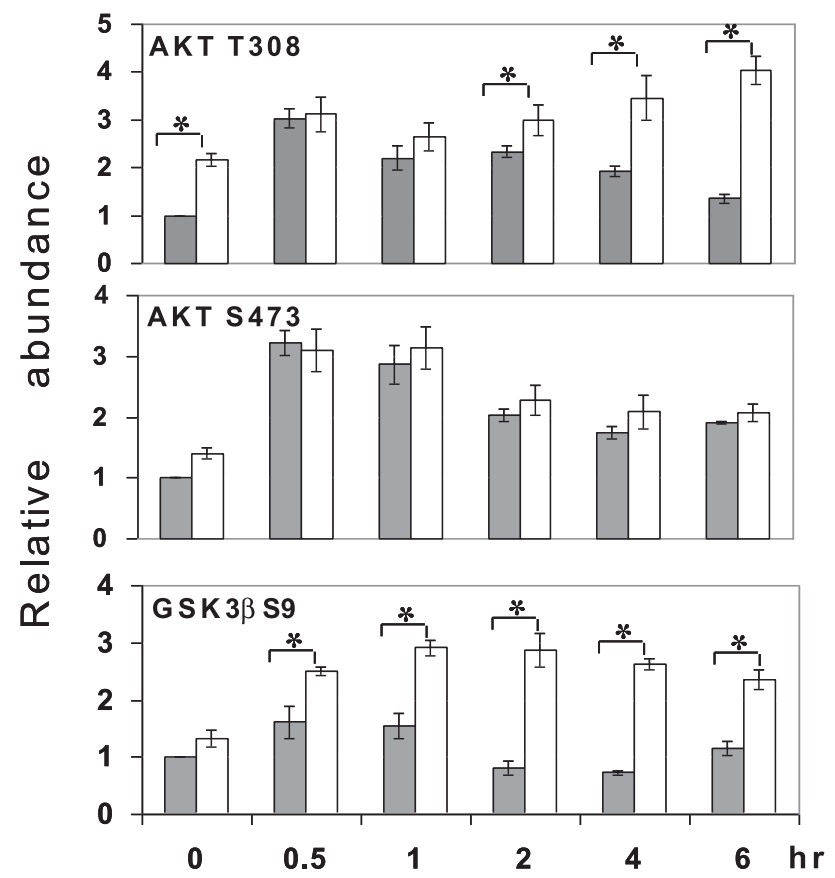

D.

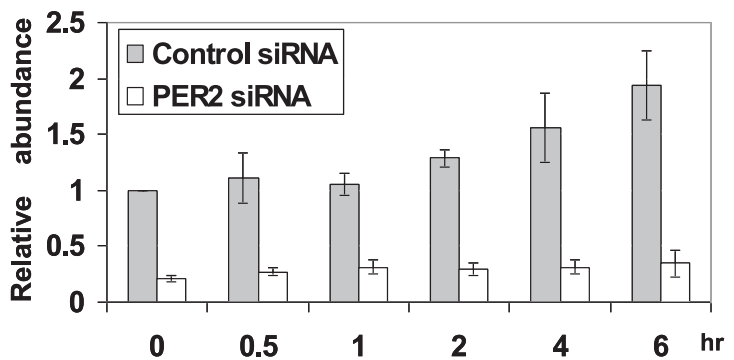

E.

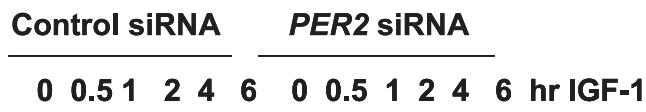

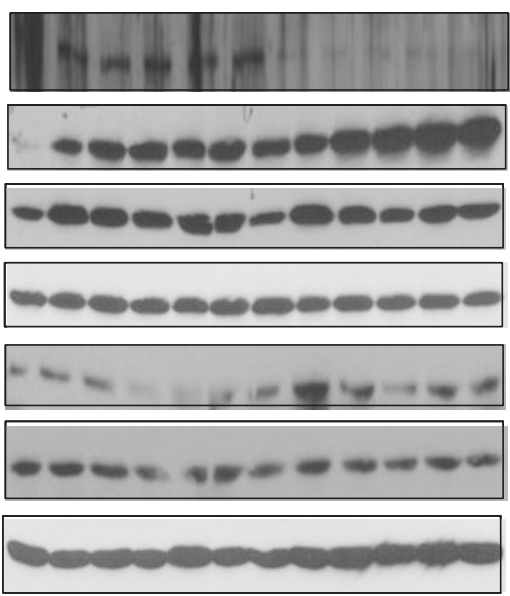

PER2

AKT T308

AKT S 473

AKT

GSK3 $\beta$ S9

GSK3 $\beta$

GAPDH

F.

Wild-type MEF Per2 $\mathrm{m} / \mathrm{m}$ MEF

$\begin{array}{llllllllllllll}0 & 0.5 & 1 & 2 & 4 & 6 & 0 & 0.5 & 1 & 2 & 4 & 6 & \mathrm{hr} \text { IGF }-1\end{array}$

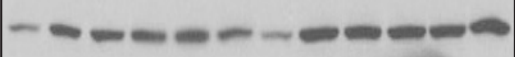

AKT T308

$-\infty-\infty-\infty-\infty$

AKT

GAPDH 
knockdown cells. To determine whether prolonged AKT T308 phosphorylation caused AKT over-activation, the phosphorylation level of GSK3 $\beta$ at the S9 site was examined. The phosphorylated GSK3 $\beta$ also remained high in PER2 knockdown cells, suggesting that growth factor induced AKT was over-activated in PER2 knockdown cells. AKT T308 is phosphorylated by PDK1. The total amount of PDK1 protein did not change in PER2 down-regulated cells (data not shown). The expression of PTEN, a negative regulator of PDK1, did not differ in the control and PER2 down-regulated cells either (Fig. 1B). We used another set of PER2 siRNA to knockdown PER2 in HCT116 cells (Fig. 1D). Again, in PER2 down-regulated cells, the phosphorylation levels of AKT T308 and GSK3 $\beta$ S9 were enhanced (Fig. 1E). IGF-1 stimulated AKT phosphorylation was also examined in the wild type and Per $2^{m / m}$ MEF cells. Per2 $2^{m / m}$ MEF cells had a prolonged AKT T308 phosphorylation after IGF-1 treatment (Fig. 1F).

AKT is also an important player in DNA damage response. DNA damage temporarily induces AKT phosphorylation and activation. This process is dependent on mismatch repair (MMR) genes (Caporali et al. 2008). We tested the kinetics of AKT phosphorylation in HCT116 cells after DNA double strand breaks were induced by doxorubicin (Dox) treatment. HCT116 is an MMR deficient cell line, therefore radiation-induced DNA damage does not cause AKT phosphorylation in HCT116 cells (Xu et al. 2010). When HCT116 cells were treated with Dox, the level of AKT T308 phosphorylation in the control cells decreased but remained high in the PER2 down-regulated cells (Figs. 2A2C). In fact, AKT T308 phosphorlation slightly increased after Dox treatment in the PER2 knockdown cells. There was no significant difference in AKT S473 levels between the control and PER2 knockdown cells (Figs. 2B and 2C). We also examined AKT phosphorylation in SW480 cells. SW480 is an MMR proficient human colon cancer cell line. As expected, AKT phosphorylation was increased at both T308 and S473 sites after Dox treatment and their levels were higher in PER2 knockdown cells (Figs. 2D-2F). After $20 \mathrm{~h}$, AKT S473 phosphorylation dropped to the basal level in both the control PER2 knockdown cells. AKT T308 phosphorylation in the control cells dropped after $20 \mathrm{~h}$ of Dox treatment but remained elevated in PER2 knockdown cells (Figs. 2E and 2F).

\section{PER2 down-regulation attenuates DNA damage response}

To determine whether PER2 down-regulation had an effect on the DNA damage response, HCT116 cells were treated with a low dose of Dox $(0.5 \mu \mathrm{mol} / \mathrm{L})$ for $2 \mathrm{~h}$ to induce DNA double strand breaks (DSBs). In the control cells, Chk2 was quickly phosphorylated at T68 site, and the Chk2 T68 level was reduced after $24 \mathrm{~h}$ (Figs. 3A and 3B). However, the DSB-induced Chk2 activation was significantly delayed in PER2 knockdown cells (Fig. 3B). Proper Chk2 T68 phosphorylation is required for subsequent cell cycle arrest and DNA damage repair after DSB. In PER2 knockdown cells, the accumulation of WEE1, a marker of G2/M cell cycle arrest, was inhibited, suggesting that DNA damage-induced cell cycle arrest was inhibited. Lower levels of cleaved caspase 3 in PER2 down-regulated cells indicated that DNA damageinduced apoptosis was attenuated (Figs. 3B and 3C). We also treated cells with a prolonged Dox exposure $(20 \mathrm{~h})$ (Figs. 3D and 3E). PER2 depleted cells had a higher level of phosphorylated Chk2 after a prolonged incubation with Dox (Fig. 3E). The protein levels of WEE1, CycB1, and p53 were lower in PER2 knockdown cells, indicating that diminished PER2 expression overrode DNA damage-induced cell cycle arrest (Fig. 3E).

To determine whether the delayed Chk2 T68 phosphorylation in PER2 knockdown cells was dependent on AKT, cells were treated with AKT1/2 inhibitor for $1 \mathrm{~h}$ before the treatment with Dox. Inhibition of AKT activity abolished the PER2 knockdown effect on Chk2 phosphorylation (Fig. 3G). There was no difference in Dox induced $\gamma$-H2AX accumulation in the control and PER2 down-regulated cells, suggesting the absence of PER2 did not affect the cells' ability to sense the DNA damage (Fig. 3G).

\section{$P E R 2$ down-regulated cells are resistant to chemotherapy drugs}

Since PER2 modulated DNA damage response, we tested whether PER2 depletion altered drug sensitivity of cancer cells. HCT116 cells with PER2 knocked down were resistant to DNA damage agents, etoposide, and Dox, compared with the control, as determined by colony formation assay (Fig. 4). On the other hand, others have shown that overexpression of PER2 sensitizes cells to irradiation and chemotherapeutic drugs (Oda et al. 2009). It is known that AKT over-activation causes cancer cells resistant to chemotherapy drugs (Henry et al. 2001; Hirose et al. 2005; Lal et al. 2009). It is likely that the drug resistant phenotype of PER2 depleted cells might be due to the enhanced AKT activation after DNA damage.

\section{Discussion}

Increasing evidence indicates that the core circadian clock protein, PER2, has a tumor suppressive function. Overexpression of PER2 causes apoptosis in the cultured cancer cells (Gery and Koeffler 2009; Hua et al. 2006, 2007). Since PER2 overexpression disrupts the circadian clock, and expressing a protein to a nonphysiological level may cause unexpected effects, we down-regulated PER2 in cancer cells in our previous studies and have found that PER2 down-regulation enhances cancer cell proliferation in vivo and in vitro (Wood et al. 2008; Yang et al. 2009). Here we report that PER2 regulates the activity of AKT. PER2 knockdown cells have a higher basal level of T308 phosphorylated AKT. It is well-known that AKT promotes cell proliferation. Enhanced AKT activity in PER2 depleted cells may contribute to the increased cell proliferation.

In PER2 knockdown cells, Chk2 T68 phosphorylation is delayed and WEE1 accumulation is inhibited after Dox treatment. It is known that medium change may synchronize the circadian clock in cultured cells. If Chk2 T68 phosphorylation is controlled by the circadian clock then the delayed Chk2 phosphorylation in PER2 knockdown cells may be due to the disrupted circadian clock. However we do not think this is the case, because with or without medium change after Dox treatment the results are not altered (medium was changed in Fig. 3B but not in Fig. 3E). In addition, we have determined that Chk2 T68 phosphorylation does not change after serum shock in cultured cells. Weel transcription is 
Fig. 2. Enhanced AKT phosphorylation after DNA damage in PER2 down-regulated cells. After siRNA treatment (Luciferase siRNA or PER2 siRNA set 1), HCT116 cells (A, B, C) and SW480 cells (D, E, F) were treated with $0.5 \mu \mathrm{mol} / \mathrm{L}$ of doxorubicin for the indicated time. The relative amounts of PER2 mRNA were determined by real time PCR. The amounts in the control cells at time point 0 were set as 1 (A, D). The amounts of phosphorylated AKT and total AKT were determined by specific antibodies (B, E). Quantification of AKT T308 and AKT S473 phosphorylation in HCT116 (C) and SW480 (F) (Control, gray bars; Per2 knockdown, empty bars). The amounts in the control cells before treatment were set as 1 .

A.

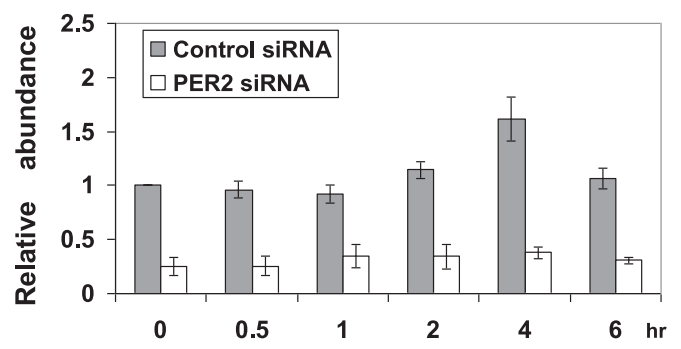

B. Control SIRNA PER2 SIRNA

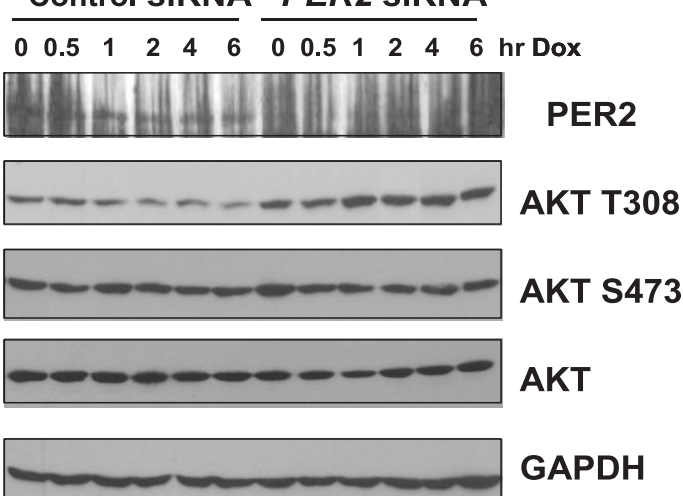

C.
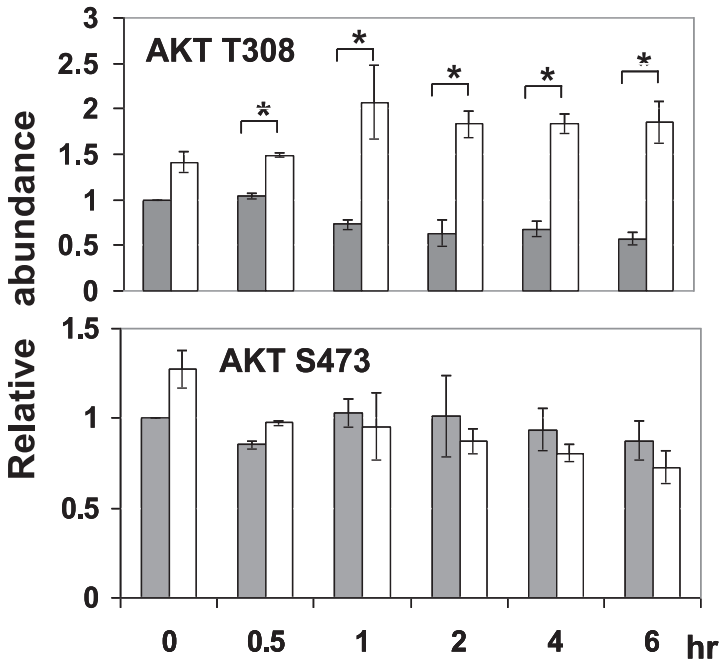

suppressed by PER/CRY complex (Matsuo et al. 2003). Knockdown of CRY leads to an elevated expression of WEE1 (Gauger and Sancar 2005). However, in PER2 knockdown cells, WEE1 accumulation is inhibited after Dox treatment. Therefore, it is unlikely that the altered WEE1 expression in PER2 knockdown cells is due to the disrupted circadian clock.

AKT overactivation is known to override DNA damageinduced cell cycle arrest and apoptosis in various cells in-
D.

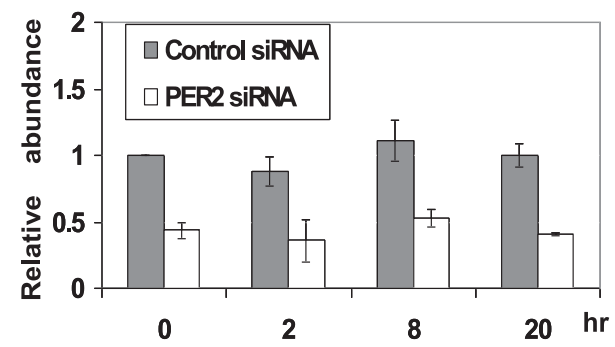

E. Control SIRNA PER2 SIRNA

$\begin{array}{lllllllllll}0 & 4 & 8 & 20 & 0 & 4 & 8 & 20 & \text { hr Dox }\end{array}$
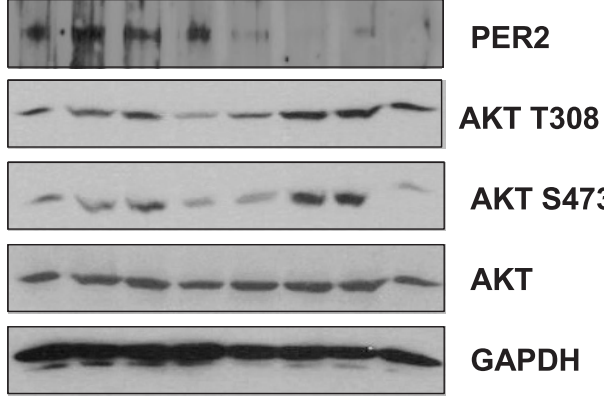

F.

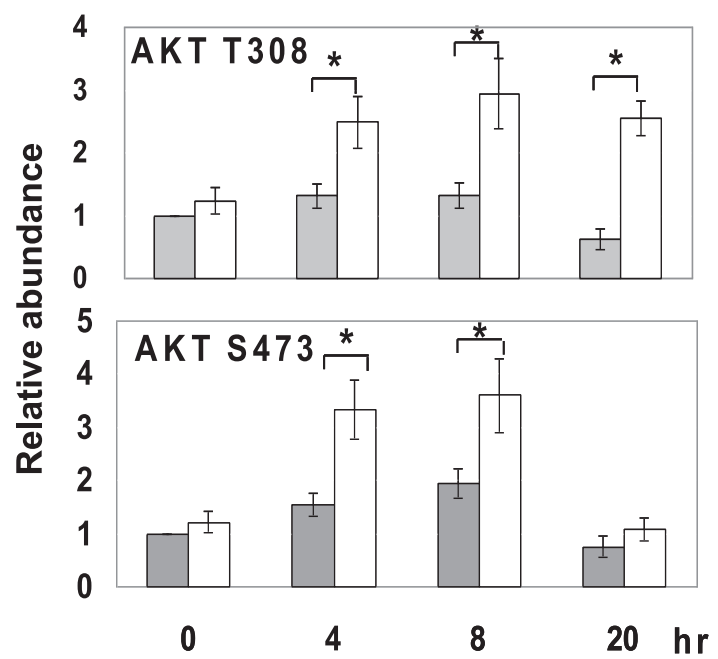

cluding HCT116 (Hirose et al. 2005; Kandel et al. 2002; $\mathrm{Xu}$ et al. 2010). Several studies have shown that AKT prevents the binding of DNA damage mediators, such as RAD51 and RPA, from forming foci at the damaged DNA sites (Plo et al. 2008; Xu et al. 2010). Therefore, active AKT interferes the tranduction of DNA damage signal from sensors to effectors. PER2 knockdown cells can still sense the damaged DNA because $\gamma$-H2AX accumulation after DNA damage is not affected by the absence of PER2. 
Fig. 3. Down-regulation of PER2 alters DNA damage response. HCT116 cells were treated with luciferase siRNA (control) or PER2 siRNA set 1 for $48 \mathrm{~h}$ followed by $0.5 \mu \mathrm{mol} / \mathrm{L}$ doxorubicin treatment for $2 \mathrm{~h}$. Cells were then incubated in the drug-free medium. Samples were taken at the indicated time points. (NT: no doxorubicin treatment). The relative amounts of PER2 mRNA were determined by real-time PCR. The amount in the NT control cells was set as 1 (A). Chk2 T68, WEE1, and caspase 3 were detected by specific antibodies. GAPDH was the loading control (B). Quantification of WEE1 and cleaved caspase 3 in the control (gray bars) and PER2 knockdown cells (empty bars). The amounts in the control cells without drug treatment were set as 1(C). After $48 \mathrm{~h}$ of siRNA treatment, HCT116 cells were incubated with $0.5 \mu \mathrm{mol} / \mathrm{L}$ of doxorubicin for $20 \mathrm{~h}$. The relative amounts of PER $2 \mathrm{mRNA}$ were determined by real-time PCR. The amount in control cells at the time point 0 was set as 1 (D). The expression of proteins determined by Western blotting. GAPDH was the loading control (E). Control or PER2 knockdown HCT116 cells were treated with AKT1/2 inhibitor $(20 \mu \mathrm{mol} / \mathrm{L})$ for $1 \mathrm{~h}$ followed by treatment with $2 \mu \mathrm{mol} / \mathrm{L}$ of doxorubicin for $2 \mathrm{~h}$. Cells were then incubated in the drug-free medium for the indicated time (NT, no Dox treatment). The relative amounts of PER2 mRNA were determined by real time PCR. The amount in the NT control cells without AKTi treatment was set as 1 (F). The levels of Chk2 T68, total Chk2, and $\gamma$-H2AX were determined by Western blotting. GAPDH was the loading control (G).

A.

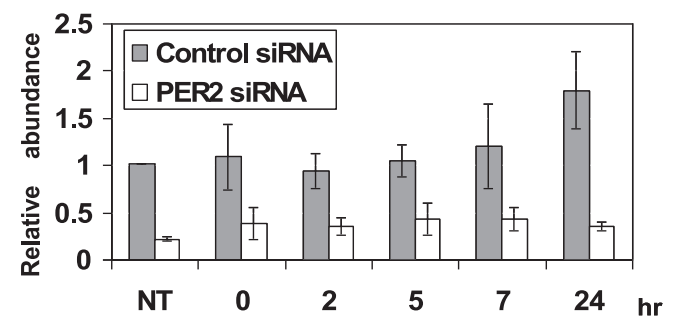

B. Control siRNA PER2 SiRNA

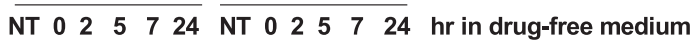

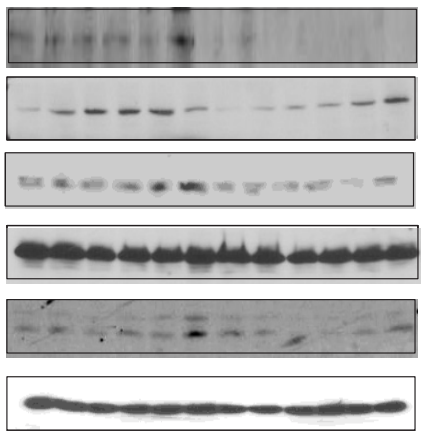

PER2

Chk2 T68

WEE1

Caspase 3

Cleaved Caspase 3

GAPDH

c.
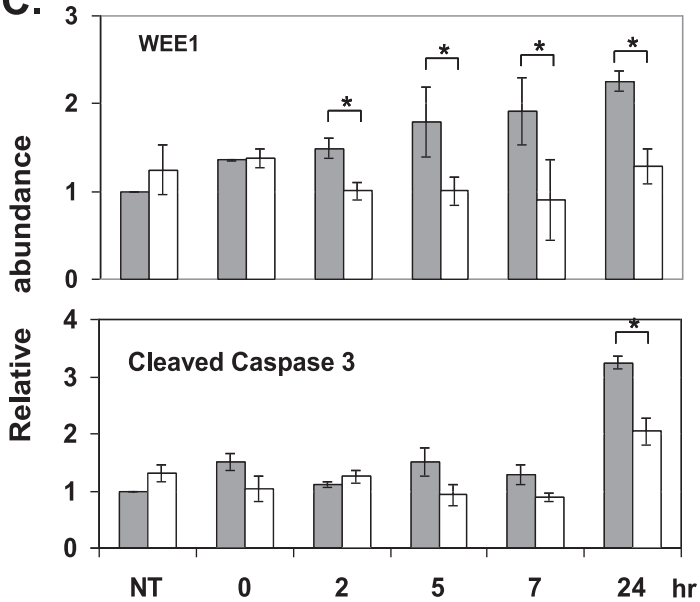

D.

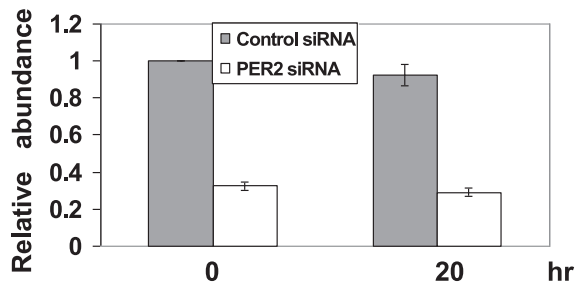

E.

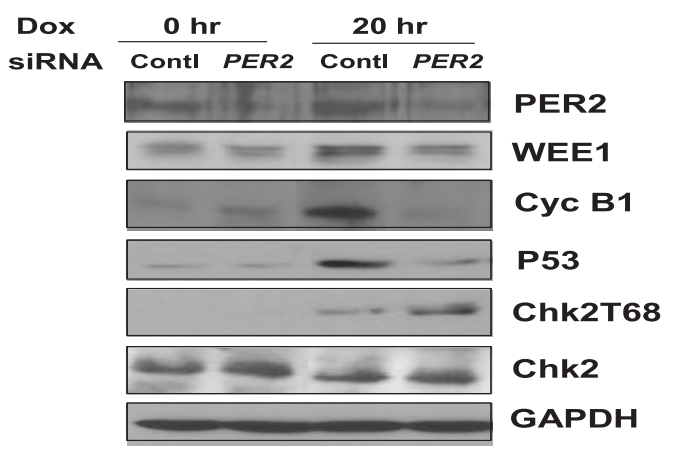

$\mathbf{F}$.

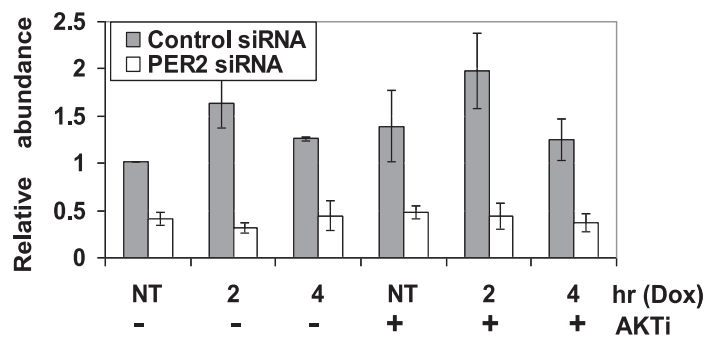

G.

siRNA Control PER2 Control PER2

NT 24 NT 24 NT 24 NT 24 in drug-free medium 
Fig. 4. Down-regulation of $P E R 2$ enhances cancer cell resistance to chemotherapy drugs. After 48 h of siRNA treatment (Luciferase siRNA or PER2 siRNA set 1), HCT116 cells were treated with the indicated concentrations of doxorubicin (A) or etoposide (B) for 24 h. Numbers of the colony were counted after 7 days of growth in the drug free medium. Colony number of the control knockdown cells without drug treatment was set as $100 \%$.

A.

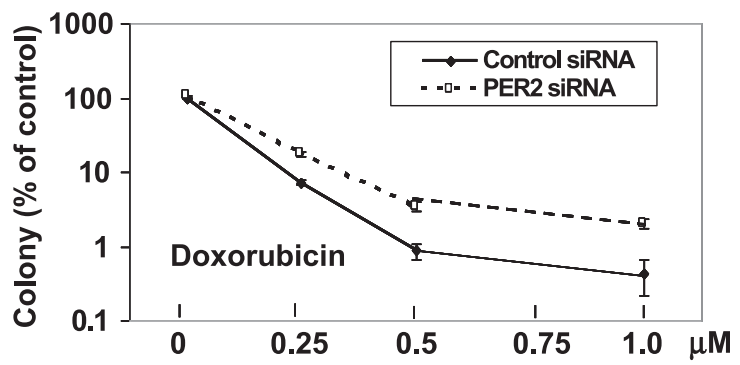

Attenuated Chk2 activation in PER2-depleted cells can be prevented by inhibiting AKT activity, suggesting that PER2 modulates DNA damage response through AKT. It has been reported that down-regulation of PERI completely abolishes DNA damage-induced Chk2 T68 phosphorylation (Gery et al. 2006). A recent report shows that PER3, another homology of PER2, is also required for Chk2 activation and overexpression of PER3 leads to Chk2 activation without DNA damage (Im et al. 2010). However, the cancer prone phenotype has never been reported in Perl or Per3 knockout mice. In PER2 down-regulated cells, Chk2 T68 phosphorylation is attenuated and delayed but not completely abolished after DNA damage. It is unclear whether PER1, PER2, and PER3 exert their tumor suppressive functions through the same pathway. In mammalian circadian clockwork, PER1 and PER2 have similar but nonredundant functions, while PER3 seems not essential for the circadian clock (Bae et al. 2001; Zheng et al. 2001).

In summary, PER2 may exert its tumor suppressive function by regulating AKT activation. We will further determine how PER2 regulates AKT activation. PER2 is a transcription factor. It may also regulate cell proliferation and DNA damage response through other mechanisms. For example, PER2 could directly regulate the expression of genes such as Cyclin $\mathrm{D}, \mathrm{C}-\mathrm{Myc}$, and $\mathrm{p} 53$. The transcription of these genes is deregulated in Per2 mutant mice (Fu et al. 2002). It is unclear whether the deregulated expression of these genes is related to AKT over activation.

\section{Acknowledgments}

We would like to thank Drs. William Hrushesky and Patricia Wood for their support during this study.

\section{References}

Bae, K., Jin, X., Maywood, E.S., Hastings, M.H., Reppert, S.M., and Weaver, D.R. 2001. Differential functions of mPer1, mPer2, and $\mathrm{mPer} 3$ in the SCN circadian clock. Neuron, 30(2): 525-536. doi:10.1016/S0896-6273(01)00302-6. PMID:11395012.

Bozulic, L., Surucu, B., Hynx, D., and Hemmings, B.A. 2008. PKBalpha/Akt1 acts downstream of DNA-PK in the DNA doublestrand break response and promotes survival. Mol. Cell, 30(2): 203-213. doi:10.1016/j.molcel.2008.02.024. PMID:18439899.

Caporali, S., Levati, L., Starace, G., Ragone, G., Bonmassar, E., Alvino, E., and D'Atri, S. 2008. AKT is activated in an ataxia-
B.

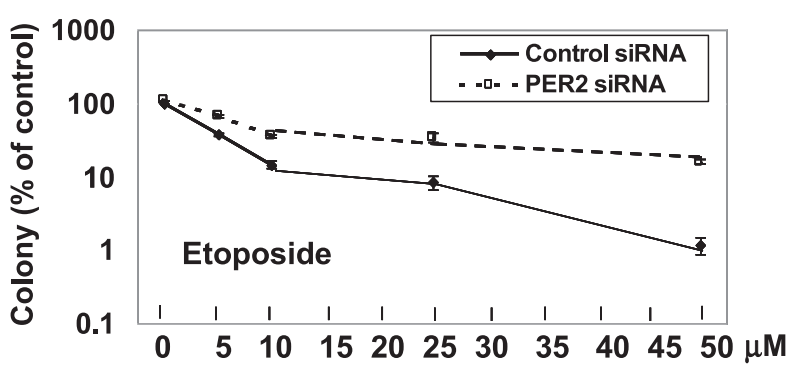

telangiectasia and Rad3-related-dependent manner in response to temozolomide and confers protection against drug-induced cell growth inhibition. Mol. Pharmacol. 74(1): 173-183. doi:10.1124/ mol.107.044743. PMID:18413665.

Chen, S.T., Choo, K.B., Hou, M.F., Yeh, K.T., Kuo, S.J., and Chang, J.G. 2005. Deregulated expression of the PER1, PER2 and PER3 genes in breast cancers. Carcinogenesis, 26(7): 1241-1246. doi:10. 1093/carcin/bgi075. PMID:15790588.

Cicenas, J. 2008. The potential role of Akt phosphorylation in human cancers. Int. J. Biol. Markers, 23(1): 1-9. PMID:18409144.

Fu, L., Pelicano, H., Liu, J., Huang, P., and Lee, C. 2002. The circadian gene Period2 plays an important role in tumor suppression and DNA damage response in vivo. Cell, 111(1): 41-50. doi:10.1016/S0092-8674(02)00961-3. PMID:12372299.

Gauger, M.A., and Sancar, A. 2005. Cryptochrome, Circadian Cycle, Cell Cycle Checkpoints and Cancer. Cancer Res. 65(15): 68286834. doi:10.1158/0008-5472.CAN-05-1119. PMID:16061665.

Gery, S., and Koeffler, H.P. 2009. Per2 is a C/EBP target gene implicated in myeloid leukemia. Integr. Cancer Ther. 8(4): 317320. doi:10.1177/1534735409352084. PMID:19926610.

Gery, S., Gombart, A.F., Yi, W.S., Koeffler, C., Hofmann, W.K., and Koeffler, H.P. 2005. Transcriptional profiling of C/EBP targets identifies Per2 as a gene implicated in myeloid leukemias. Blood, 106(8): 2827-2836. doi:10.1182/blood-2005-01-0358. PMID: 15985538 .

Gery, S., Komatsu, N., Baldjyan, L., Yu, A., Koo, D., and Koeffler, H.P. 2006. The circadian gene Per1 plays an important role in cell growth and DNA damage control in human cancer cells. Mol. Cell, 22(3): 375-382. doi:10.1016/j.molcel.2006.03.038. PMID: 16678109 .

Henry, M.K., Lynch, J.T., Eapen, A.K., and Quelle, F.W. 2001. DNA damage-induced cell-cycle arrest of hematopoietic cells is overridden by activation of the PI-3 kinase/Akt signaling pathway. Blood, 98(3): 834-841. doi:10.1182/blood.V98.3.834. PMID: 11468186.

Hirose, Y., Katayama, M., Mirzoeva, O.K., Berger, M.S., and Pieper, R.O. 2005. Akt activation suppresses Chk2-mediated, methylating agent-induced $\mathrm{G} 2$ arrest and protects from temozolomide-induced mitotic catastrophe and cellular senescence. Cancer Res. 65(11): 4861-4869. doi:10.1158/0008-5472.CAN-04-2633. PMID: 15930307.

Hua, H., Wang, Y., Wan, C., Liu, Y., Zhu, B., Yang, C., et al. 2006. Circadian gene mPer2 overexpression induces cancer cell apoptosis. Cancer Sci. 97(7): 589-596. doi:10.1111/j.1349-7006. 2006.00225.x. PMID:16827798.

Hua, H., Wang, Y., Wan, C., Liu, Y., Zhu, B., Wang, X., et al. 2007. Inhibition of tumorigenesis by intratumoral delivery of the 
circadian gene mPer2 in C57BL/6 mice. Cancer Gene Ther. 14(9): 815-818. doi:10.1038/sj.cgt.7701061. PMID:17589433.

Iacobelli, S., Innominato, P.F., Piantelli, M., Bjarnason, G., Coudert, B., Focan, C., et al. 2008. Tumor clock protein PER2 as a determinant of survival in patients receiving oxaliplatin-5-FUleucovorin as first-line chemotherapy for metastatic colorectal cancer. J. Clin. Oncol. 26 May Suppl., Abstract No. 11032.

Im, J.-S., Jung, B.-H., Kim, S.-E., Lee, K.-H., and Lee, J.-K. 2010. Per3, a circadian gene, is required for chk2 activation in human cells. FEBS Lett. 584(23): 4731-4734. doi:10.1016/j.febslet.2010. 11.003. PMID:21070773.

Kandel, E.S., Skeen, J., Majewski, N., Di Cristofano, A., Pandolfi, P.P., Feliciano, C.S., et al. 2002. Activation of Akt/protein kinase B overcomes a $\mathrm{G}(2) / \mathrm{m}$ cell cycle checkpoint induced by DNA damage. Mol. Cell. Biol. 22(22): 7831-7841. doi:10.1128/ MCB.22.22.7831-7841.2002. PMID:12391152.

Lal, M.A., Bae, D., Camilli, T.C., Patierno, S.R., and Ceryak, S. 2009. AKT1 mediates bypass of the G1/S checkpoint after genotoxic stress in normal human cells. Cell Cycle, 8(10): 15891602. doi:10.4161/cc.8.10.8547. PMID:19377290.

Liang, J., and Slingerland, J.M. 2003. Multiple roles of the PI3K/PKB (Akt) pathway in cell cycle progression. Cell Cycle, 2(4): 336342. doi:10.4161/cc.2.4.433. PMID:12851486.

Liao, Y., and Hung, M.C. 2010. Physiological regulation of Akt activity and stability. Am. J. Transl. Res. 2(1): 19-42. PMID: 20182580.

MacDonald, B.T., Tamai, K., and He, X. 2009. Wnt/beta-catenin signaling: components, mechanisms, and diseases. Dev. Cell, 17(1): 9-26. doi:10.1016/j.devcel.2009.06.016. PMID:19619488.

Matsuo, T., Yamaguchi, S., Mitsui, S., Emi, A., Shimoda, F., and Okamura, H. 2003. Control mechanism of the circadian clock for timing of cell division in vivo. Science, 302(5643): 255-259. doi:10.1126/science.1086271. PMID:12934012.

Oda, A., Katayose, Y., Yabuuchi, S., Yamamoto, K., Mizuma, M., Shirasou, S., et al. 2009. Clock gene mouse period2 overexpression inhibits growth of human pancreatic cancer cells and has synergistic effect with cisplatin. Anticancer Res. 29(4): 12011209. PMID: 19414365.

Oshima, T., Takenoshita, S., Akaike, M., Kunisaki, C., Fujii, S., Nozaki, A., et al. 2011. Expression of circadian genes correlates with liver metastasis and outcomes in colorectal cancer. Oncol. Rep. 25(5): 1439-1446. doi:10.3892/or.2011.1207. PMID: 21380491.

Plo, I., Laulier, C., Gauthier, L., Lebrun, F., Calvo, F., and Lopez, B.S. 2008. AKT1 inhibits homologous recombination by inducing cytoplasmic retention of BRCA1 and RAD51. Cancer Res. 68(22): 9404-9412. doi:10.1158/0008-5472.CAN-08-0861. PMID: 19010915.

Reppert, S.M., and Weaver, D.R. 2002. Coordination of circadian timing in mammals. Nature, 418(6901): 935-941. doi:10.1038/ nature00965. PMID:12198538.

Wang, C.-Y., Wen, M.-S., Wang, H.-W., Hsieh, I.-C., Li, Y., Liu, P.-Y., et al. 2008. Increased vascular senescence and impaired endothelial progenitor cell function mediated by mutation of circadian gene Per2. Circulation, 118(21): 2166-2173. doi:10. 1161/CIRCULATIONAHA.108.790469. PMID:18981300.

Winter, S.L., Bosnoyan-Collins, L., Pinnaduwage, D., and Andrulis, I.L. 2007. Expression of the circadian clock genes Per1 and Per2 in sporadic and familial breast tumors. Neoplasia, 9(10): 797-800. doi:10.1593/neo.07595. PMID:17971899.

Wood, P.A., Yang, X., Taber, A., Oh, E.Y., Ansell, C., Ayers, S.E., et al. 2008. Period 2 mutation accelerates ApcMin/+ tumorigenesis. Mol. Cancer Res. 6(11): 1786-1793. doi:10.1158/1541-7786. MCR-08-0196. PMID:19010825.

Xu, N., Hegarat, N., Black, E.J., Scott, M.T., Hochegger, H., and Gillespie, D.A. 2010. Akt/PKB suppresses DNA damage processing and checkpoint activation in late G2. J. Cell Biol. 190(3): 297-305. doi:10.1083/jcb.201003004. PMID:20679434.

Yang, X., Wood, P.A., Oh, E.Y., Du-Quiton, J., Ansell, C.M., and Hrushesky, W.J. 2009. Down-regulation of circadian clock gene Period 2 accelerates breast cancer growth by altering its daily growth rhythm. Breast Cancer Res. Treat. 117(2): 423-431. doi:10.1007/s10549-008-0133-z. PMID:18651214.

Zeman, M., Vician, M., Monosikova, J., REis, R., and Herichova, I. 2008. Deregulated expression of per2 gene in human colorectal cancer. Mol. Med. Reports, 1: 599-603.

Zheng, B., Albrecht, U., Kaasik, K., Sage, M., Lu, W., Vaishnav, S., et al. 2001. Nonredundant roles of the mPer1 and mPer2 genes in the mammalian circadian clock. Cell, 105(5): 683-694. doi:10. 1016/S0092-8674(01)00380-4. PMID:11389837. 